Oral Section

\title{
Pre stimulation by gibberellic acid and the effect of extremely diluted agitated gibberellic acid on wheat stalk growth
}

\author{
Sonja Hribar-Marko, Waltraud Scherer-Pongratz, \\ Harald Lothaller, Peter Christian Endler
}

Interuniversity College for Health and Development Graz / Castle of Seggau, Austria

\begin{abstract}
Background: In previous multicentre studies[1,2], the influence of a homeopathic ultra high dilution of gibberellic acid on wheat growth was scrutinized. Data showed that this test dilution slowed down stalk growth when experiments were performed in autumn season.
\end{abstract}

Aim: To test the hypothesis that pre treatment of grains with high concentrations of gibberellic acid will enhance the effect of the ultra high dilution of the plant hormone

Methods: Grains of winter wheat (Triticum aestivum) were observed under the influence of extremely diluted gibberellic acid $\left(10^{-30}\right)$ prepared by stepwise dilution and agitation according to a protocol derived from homeopathy ("G30x"). Analogously prepared water was used for control ("W30x"). Grains (500 or 1000 per group) were pre treated with (not agitated) gibberellic acid 10-5, 10-4 and $10^{-3}$ ("Ge-5, Ge-4, Ge-3") or with water ("W") for control prior to treatment with G30x or W30x. Seedlings were allowed to develop under standardized conditions for 7 days; plants were harvested and stalk lengths were measured.

Results: With regard to pre treatment, it can be seen that the groups treated with Ge-3 showed most growth, followed by the Ge-4 groups, the Ge- 5 groups and the non pre treated W groups. This decline is modulated by the application of G30x and W30x (figure 1). The lower the pre treatment concentration of G, the more marked is a slowing down effect of G30x versus W30x.

Conclusion: The hypothesis that pre treatment of grains with high concentrations of gibberellic acid will enhance the effect of G30x had to be rejected. In contrast, G30x slowed down stalk growth in the W group with $\mathrm{p}<0.001$ but only moderately in the Ge- 5 and Ge-4 group and not at all in the Ge-3 group.

Keywords: homeopathy, wheat stalk growth, gibberellic acid, high dilution

\section{References:}

[1] Pfleger A., Hofäcker J., Scherer-Pongratz W., Lothaller H., Reich C., Endler P.C. The effect of extremely diluted agitated gibberellic acid (10e-30) on wheat seedling development - a two researcher study. Complementary Therapies in Medicine 2011; 19: 164-169. 
[2] Endler PC, Matzer W, Reich C, Reischl T, Hartmann AM, Thieves K, Pfleger A, Hofäcker J, Lothaller H, Scherer-Pongratz W. Seasonal variation of the effect of extremely diluted agitated gibberellic acid (10e-30) on wheat stalk growth - a multi researcher study. The Scientific World Journal 2011; 11: 1667-1678.

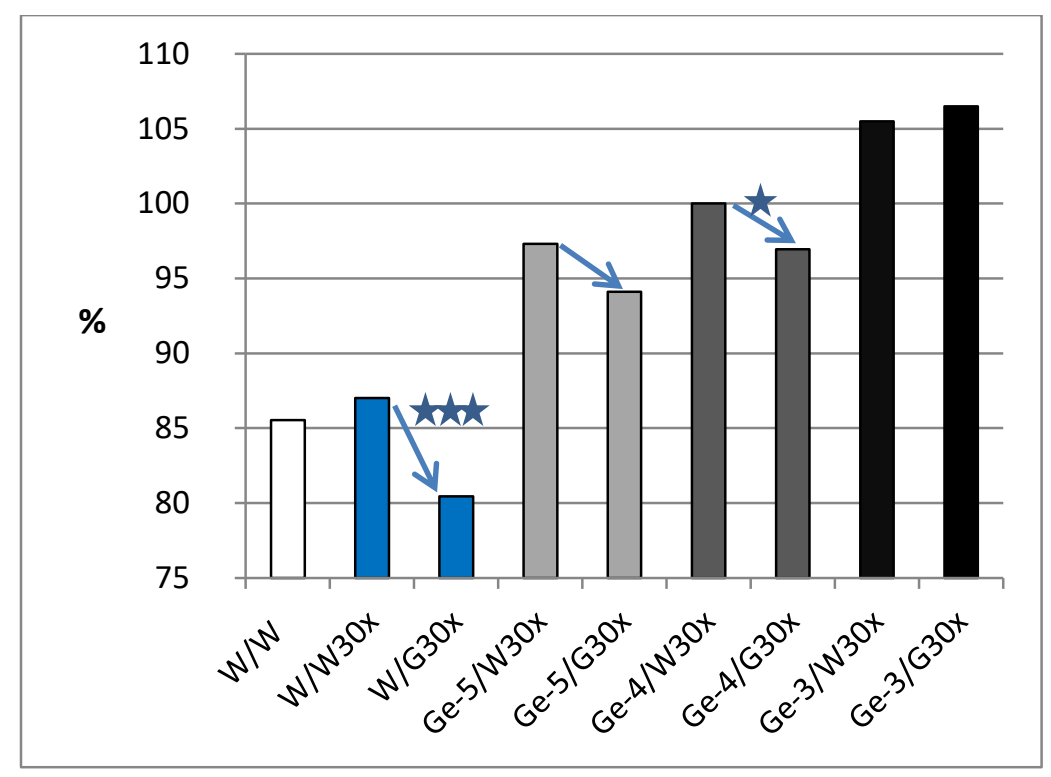

Figure 1: Stalk length in percent of groups as indicated in the abscissa. ${ }^{* * *}, \mathrm{p}<0.001 ;{ }^{*}, \mathrm{p}<0.01$.

\section{(c) EY-NC-ND Licensed to GIRI}

Support: authors declare that this study received no funding

Conflict of interest: authors declare there is no conflict of interest

Received: 01 June 2012; Revised: 08 August 2012; Published: 30 September 2012.

Correspondence author: Peter Christian Endler college@inter-uni.net

How to cite this article: Hribar-Marko S, Scherer-Pongratz W, Lothaller H, Endler PC. Pre stimulation by gibberellic acid and the effect of extremely diluted agitated gibberellic acid on wheat stalk growth. Int J High Dilution Res [online]. 2012 [cited YYYY Month dd]; 11(40):124-125. Proceedings of the XXVI GIRI Symposium; 2012 Sep 20-22; Florence (Italy). GIRI; 2012; Available from: http://www.feg.unesp.br/ ojs/index.php/ijhdr/article/view/605/577 